\title{
Relating Problem-Solving Approach to Turn-Taking in Communication of Design Teams
}

\author{
Nikola HORVAT, Stanko ŠKEC, Marija Majda PERIŠIĆ, Nenad BOJČETIĆ
}

\begin{abstract}
This paper builds on the turn-taking model of verbal communication and proposes a framework for relating the problem-solving style to the turn-taking model. The framework aims at enabling a more comprehensive investigation of verbal communication in team design activities. An empirical study has been conducted to test the framework and identify the relationship between individuals' problem-solving styles and the corresponding percentages of turn transitions. The results show a non-linear relationship between diversity in Orientation to Change and Ways of Deciding dimensions of problem-solving style and the percentage of turn transitions. The non-linear relationship has been explained by referring to team diversity-related theories on information/decision-making and social categorisation. The empirical study demonstrated that the framework is useful for providing a more comprehensive description of communication patterns within design teams.
\end{abstract}

Keywords: design team; problem-solving style; turn-taking; verbal communication

\section{INTRODUCTION}

Product development organisations often utilise design teams for design related work [1]. By sharing knowledge, ideas and resources, design teams can outperform work done by individuals [1]. Therefore, design activities such as concept generation and design review are often conducted as team activities [2].These team activities are core to the design process [3], and understanding factors which might influence them is considered crucial for the improvement of the design process and outcome.

In studies of team design activities, researchers often use verbal communication among team members to obtain insights into their cognitive activities [4]. These investigations are driven by the premise that most factors that affect and contribute to designing in teams (e.g. trust, social skills, role, relationship and problem-solving approach) are underpinned by communication [4] Understanding the effect of these factors might contribute to the overall understanding of team design activities. For example, designers' approach to solving problems has already been found to influence both the design process [5] and design outcomes [6]. However, the relationship between problem-solving (PS) approach and communication within a design team has rarely been investigated [6].

As a step towards understanding the effect of designers' approach to solving problems on the team's verbal communication, this paper addresses the following research question:

- What is the relationship between individuals' problem solving approach and their verbal communication during team design activities?

\section{BACKGROUND}

\subsection{Analysis of Verbal Communication}

In conversation analysis approaches [7], a common prerequisite for the investigation of verbal communication is to capture and represent communication of interest in an adequate format (e.g. voice/video recordings, transcripts). The investigation begins with parsing the verbal communication into smaller segments of speech, referred to as units of analysis. Unit of analysis is defined in accordance with the study aims, and it can be based on [8]: duration (e.g. one-minute segments), sentence (i.e. one sentence represents one segment), content (researcher defines and interprets segments based on a content of communication), or turn-taking (TT) [9] in communication. In the field of design research, most common units of analysis are content based. For example, Stempfle and Badke-Schaub [1] used communication acts as the unit of analysis which they defined as: "a statement concerning a specific subject" [1]. Gero and Kannengiesser [10] parsed verbal communication using design issues, which are the main constructs of the Function-BehaviourStructure (FBS) ontology. Based on the analysis of interpersonal responses with Interaction Dynamics Notation (IDN), Sonalkar et al. [2] captured interaction among design team members. Goldschmidt [8] defined design moves as process steps that change the design situation and used them as constructs of Linkography [8].

The unit of analysis in $T T$ is a turn-constructional unit (TCU), which starts with a verbal utterance of any team member and finishes with a transition-relevance place (TRP) [9]. There are several ways to determine TRP, such as grammar, phonetic realisation or recognisable action in context. After a TRP, there are three possible scenarios: silence until someone starts speaking, another person starts speaking, or the same person continues with next TCU.

Units of analysis which are based on the content of utterances usually provide more information about the communication matter than TT. However, they typically do not reveal the communication structure, which is considered important in analyses of design team activities [11]. Furthermore, content-based units of analysis require researchers' interpretation of communication. Hence, a researcher should assess inter-coder reliability to increase the internal validity of the study [12]. This methodological procedure consequently increases coding time when compared to TT. On the other hand, parsing the communication in accordance to the $T T$ usually has high inter-coder reliability [12].It reflects only the information about the speaker and timing of a verbal utterance, while content information is excluded from the process. As such, development of a TT model can be used as a basis for understanding verbal communication.

Although TT modelling has not been extensively employed within design research, there are a few examples of its use. Gero and Kan [13] performed a sequential 
analysis using the $T T$ model to study communication patterns in a team of seven people during a brainstorming session. Gero et al. [14] observed the same team by comparing transitions between team members using two communication modelling approaches - TT and design issues. Building on the findings of this comparison, Jiang and Gero [12] suggested that using Linkography [8] to link conversational turns provides sufficient information for determining structural patterns of communication in design teams. Wulvik et al. [15] developed the Temporal Static Visualisation (TSV) tool which uses conversational turns and number of spoken words to calculate speaker score among participants in group discussion.

Studies listed above demonstrate the applicability of $T T$ in terms of verbal communication analysis, especially when $T T$ is coupled with other approaches such as Linkography and counting the number of spoken words. However, previous design research studies of $T T$ observed designers without considering their individual characteristics (e.g. personality of team members, PS approach, cognitive style), thus limiting the findings. A PS approach is already found to influence both the design process [5] and outcomes [6], and it is suggested that it affects verbal communication in design teams [16].

\subsection{Designers' PS Style}

PS style describes individual preferences to plan and carry out generating and focusing activities, and it will be used as a construct to describe designers' approach to solving problems. In contrast to one's capability to solve problems (which is changing over time since it depends on a designer's knowledge and experience), individual's PS style is formed early and is resistant to change $[5,17]$.

Established approach to assess PS style is proposed by Treffinger et al. [16] who integrated three theories of individual characteristics (psychological type, learning style, and cognitive style) in the theory of Creative Problem Solving [18]. The authors [16] proposed three dimensions of a PS style: Orientation to Change $(O C)$, Manner of Processing $(M P)$, and Ways of Deciding ( $W D) . O C$ deals with person's perceived preferences and dispositions for dealing with the structure, novelty, authority, and information search when managing change and creatively solving problems [19]. $M P$ is defined as a measure of individual preferences for processing information "externally" (e.g. developing ideas through communication) or "internally" (e.g. quiet reflection) [19]. $W D$ describes individuals' preferences while balancing task concerns and personal or interpersonal needs [19]. All three dimensions are assumed to influence the formation of team communication structure [16]. To assess the PS style using these three dimensions, Selby et al. [19] developed a VIEW assessment method. In the assessment method, theoretical scores are ranging from 18 (Explorer) to 126 (Developer) for $O C$ dimension, from 8 (External) to 56 (Internal) for $M P$ dimension, and from 8 (Person) to 56 (Task) for $W D$ dimension. VIEW assessment has been tested for reliability and validity using both quantitative and qualitative methods [20]. Using the VIEW assessment, Martinec et al. [21] found a correlation between the VIEW dimensions ( $O C$ and $W D$ ) and the verbal engagement of team members during conceptual design task. The three
VIEW dimensions correlate [20] with other measures used in design research, such as Myers-Briggs Type Indicator (MBTI) and Kirton's Adaptation Innovation (KAI) inventory [17], thus allowing comparison of the findings.

The underlying Adaptation-Innovation theory of KAI inventory proposes that innovators generally produce more ideas and tolerate fuzzy problems more than adaptors [17]. However, in the study of a team idea generation activity, Lopez-Mesa et al. [22] did not find the influence of PS style on the number of solutions but rather suggested that PS style is related to the frequency of reflections and the percentage of non-obvious solutions [22]. Mulet et al. [23] also used KAI to assess PS style and found that innovative teams have a slightly higher percentage of contentinteractions and interactions between team members, as opposed to adaptive teams. Sarkar and Chakrabarti [24] aimed at mapping the KAI scores on the design outcomes of individual design sessions. However, since all sampled participants were assessed as innovative, the authors were unable to map the KAI scores to the design outcomes [24]. Sonalkar et al. [6] also used KAI inventory to assess designers' cognitive styles and investigated their influences on the interaction between individuals based on IDN coding scheme [2] and the design outcome.

In addition to approaches that quantify PS style (e.g. VIEW, KAI), researchers have also used qualitative approaches to compare PS styles. Most notable, Eisentraut [5] proposed five categories (goal elaboration, information gathering, prognosing, planning and acting, and effect monitoring) to analyse the PS process after each design activity. With the qualitative elaboration of the PS process utilising this scheme, it is possible to compare two or more PS processes and identify differences between them. These differences can then be related to the success of the PS process.

Even though the theoretical literature suggests that PS style relates to verbal communication, the empirical studies (e.g. [6]) did not depict such relationship. Therefore, to help in furthering these studies, a framework which relates the PS style to verbal communication in terms of $T T$ is proposed.

\section{RESEARCH METHODOLOGY}

As a research methodology, this study applied the Design Science Research framework which consists of the three cycles [25]: relevance cycle, design cycle, and rigour cycle. Within the relevance cycle, a problem space was set by reviewing the literature on verbal communication analysis and PS style assessment techniques. Relevance cycle resulted in defined constructs of the framework. In the design cycle, insights from the relevance cycle were integrated into the proposed framework. The proposed framework was then evaluated with an empirical exploratory study. The empirical study analysed the relationship between individuals' PS style and verbal communication in a design team working on a conceptual design task. Within the third, rigour cycle, results of the empirical study were compared with existing literature as a step towards validation of the proposed framework. 


\section{FRAMEWORK FOR RELATING THE PS STYLE TO TURN-TAKING}

The proposed framework utilises the $T T$ model of communication proposed by Sacks et al. [9]. In the model, verbal utterances are modelled as TCUs determined with the beginning of one's vocal expression (start of TCU) and TRP (end of TCU). Adjacent TCUs are connected with turn transitions, thus allowing an analysis of the communication structure [26]. When studying transitions, it is common to assume that there is only one speaker at the time [9]. This simplification enables easier analysis and reduces the segmentation time, but also introduces some error into the model. However, the resulting erroneous segments are both rare [21] and brief [9], so the simplification should not have a notable effect on the obtained results.

Fig. 1 presents the framework in which the PS styles of team members are integrated within the $T T$ model. This integration allows a more comprehensive description of verbal communication patterns within a team design activity. Following the proposed framework and based on the insights from the PS style literature, the empirical study was conducted to explore how PS style relates to the number of turn transitions - one of the measures from the TT model. Turn transitions were previously used for analysing sequences of speech among team members and building a communication structure [26].

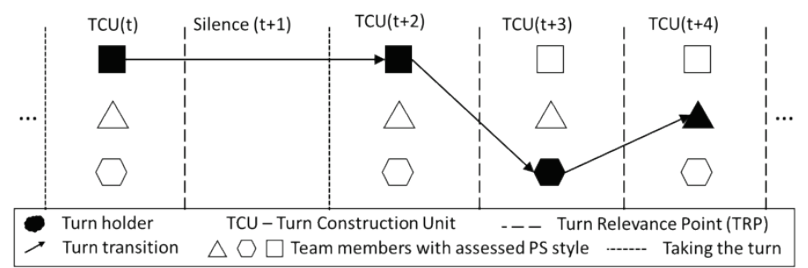

Figure 1 Coupling the PS style and the turn-taking model; built on [9]

\section{EMPIRICAL STUDY SETUP}

The empirical study was designed as a laboratory experiment in which teams were tasked to generate concepts for a given problem. Laboratory-based studies are chosen because they allow control of the independent variables, thus facilitating the exploration of relationships between the variables [27]. Laboratory-based studies usually use students as participants [28] and are frequently criticised from the aspect of ecological validity. However, previous studies have shown that conversational activities during ideation in the laboratory-based studies are similar to conversational activities observed in practice [3].

Even though this paper aims to propose a framework which can be applied to various team activities in design, the empirical part focuses on concept generation activity for three reasons. First, a concept generation is a context for which PS style construct has already been tested [16], thus enhancing the empirical structural validity of the study [29]. Next, a concept generation activity is one of the core design activities [3] and selecting it as a case will directly show the usefulness of the framework in the design field. Third, concept generation has been frequently studied, which provides the opportunity to compare the study findings with the current literature and consequently ensures the empirical performance validity [29].
Within the experiment, teams were given 60 minutes to develop a concept of a mobile key-organiser (please consult Martinec et al. [21] for additional information). Such design task was considered appropriate because the participants use keys on a daily basis, and they were able to understand the problem without additional information gathering during the session. Similar to the majority of conceptual design problems, this problem was ill-defined and included only a few requirements and constraints.

All the sessions had to be recorded to capture teams' verbal communication. Therefore, the experimental setup included: two video recording cameras, one audio recorder, a digital notebook with a ballpoint pen for sketching and drafting, and a wall-mounted screen. Following the experimental procedure, a pilot study has been conducted to ensure the adequacy of the room setup, problem description, timing constraint as well as to identify any other flaws in the procedure.

\subsection{Selection of Participants}

The task described above was given to four teams, each composed of three members. Small-scale studies are commonly used in descriptive studies, making them appropriate for the identification of trends and possible research directions [30]. A team size of three is chosen as a balance between conflicting opinions on optimum team size. On the one hand, small teams (e.g. two-member teams) in comparison to larger ones, show a higher sensitivity of outcome to one strong/weak (in terms of personality, skills, knowledge etc.) participant in a team [30]. On the other hand, smaller teams show a higher level of tension, which prevents them from quickly settling on a single idea, and therefore makes them suitable for creative problem-solving [30]. Smaller teams also take less time to reach a decision than larger teams. Furthermore, large teams sometimes engage in multiple parallel discussions, which may be hard to follow by team members, but also hard to analyse [30]. Therefore, threemember teams were used in this study, similar to other studies of teams in the design field (see, for example [3, 6]).

The participants were selected from the group of thirdand fourth-year students of mechanical engineering. Chosen participants are similar in each of the four contextdescribing aspects proposed by Cash et al. [31]: Technical, Historical, Social, and Cultural Environment. The technical environment was the same for all teams and is already described in the previous section. Regarding historical scope, all participants attended the same university, and most of them have been enrolled in courses related to product development. Moreover, all participants completed a one-semester project-based learning course in which they developed a prototype of a mechatronic device. During the course, students have experienced various phases of product development, such as planning, conceptual and detail design, and testing. Choosing participants from the same university, with the same nationality and same design specialisation (engineering design) also ensured homogeneity in the cultural and social dimension. Gender differences were neglected for this research, but it is worth mentioning that this study had six male and six female participants. 


\subsection{Assessing PS Style and Team Formation}

PS style of participants has been assessed during a workshop led by a qualified VIEW professional. During the workshop, a concept of PS style and VIEW constructs has been introduced to participants. Participants then filled in the online questionnaire, which was assessed by the professional. Questionnaire resulted in PS style across three dimensions (Tab. 1) ranging from 40 to 93 (Mean $=$ 74.7, Standard Deviation $(S D)=15.1)$ in $O C$ dimension, from 22 to $54($ Mean $=31.3, S D=8.7)$ in $M P$ dimension, and from 19 to $52($ Mean $=40.3, S D=10.6)$ in $W D$ dimension.

Considering the score in PS style, three-member teams were formed so that they differ in two team level constructs, their average VIEW scores and the diversity of the PS style within a team. This procedure was chosen since it allows investigation of individual PS style in the context of these two team level constructs. Team formation is shown in Tab. 1.

Table 1 Team formation and participants' PS style

\begin{tabular}{|c|c|c|c|c|c|c|c|}
\hline Team 1 & $O C$ & $M P$ & $W D$ & Team 2 & $O C$ & $M P$ & $W D$ \\
\hline$P 1$ & 81 & 26 & 32 & $P 4$ & 88 & 31 & 52 \\
\hline$P 2$ & 76 & 34 & 19 & $P 5$ & 77 & 26 & 51 \\
\hline$P 3$ & 68 & 30 & 37 & $P 6$ & 75 & 24 & 52 \\
\hline Team 3 & $O C$ & $M P$ & $W D$ & Team 4 & $O C$ & $M P$ & $W D$ \\
\hline$P 7$ & 91 & 34 & 42 & $P 10$ & 40 & 54 & 51 \\
\hline$P 8$ & 93 & 33 & 33 & $P 11$ & 56 & 24 & 35 \\
\hline$P 9$ & 82 & 22 & 47 & $P 12$ & 69 & 38 & 32 \\
\hline
\end{tabular}

\subsection{Coding the Verbal Communication}

Video recordings were coded based on the TT model presented in Section 4. Verbal communication within concept generation activity was divided into TCUs with annotated turn holders for each TCU. Although the TT model can be used to separate utterances of a single team member based on the TRPs, such cases are not considered in this experiment since they do not affect the number of interpersonal turn transitions. Thus, silences from the proposed framework were not coded, and adjacent utterances where the same team member holds the turn are segmented as one, i.e. the TRP only exists in the place where another team member takes the turn. In cases when more than one team member speaks at the time, TCU has been assigned to the team member who appeared to the coder as more dominant (either the coder observed that a non-speaking team member had been looking at one of the speaking team members, or the less dominant team member repeated himself afterwards).

\section{ANALYSIS AND RESULTS}

Before presenting the results on the number of turn transitions, outcomes from the concept generation sessions are outlined. Describing insights about developed concepts might give a better understanding of the activity context and improve the study reliability [30].

In total, teams developed 29 concepts (for detailed sketching analysis, please consult Nikolić et al. [32]). At the end of the session, each of teams had to decide on only one final concept (Fig. 3). Team 1 proposed housing with compartments for keys containing a push-push springbased mechanism to retrieve a key from the slot. Team 2 proposed a modular concept with each module holding one key on the keychain hole. A sliding mechanism is used to rotate a key around the keychain hole pivot, thus positioning the key in a ready-to-use mode. Team 3 proposed a solution which has textile to prevent the damage caused by the keys. Team 4 proposed a solution based on the principle of a handheld fan where the user can quickly scan all the carried keys.

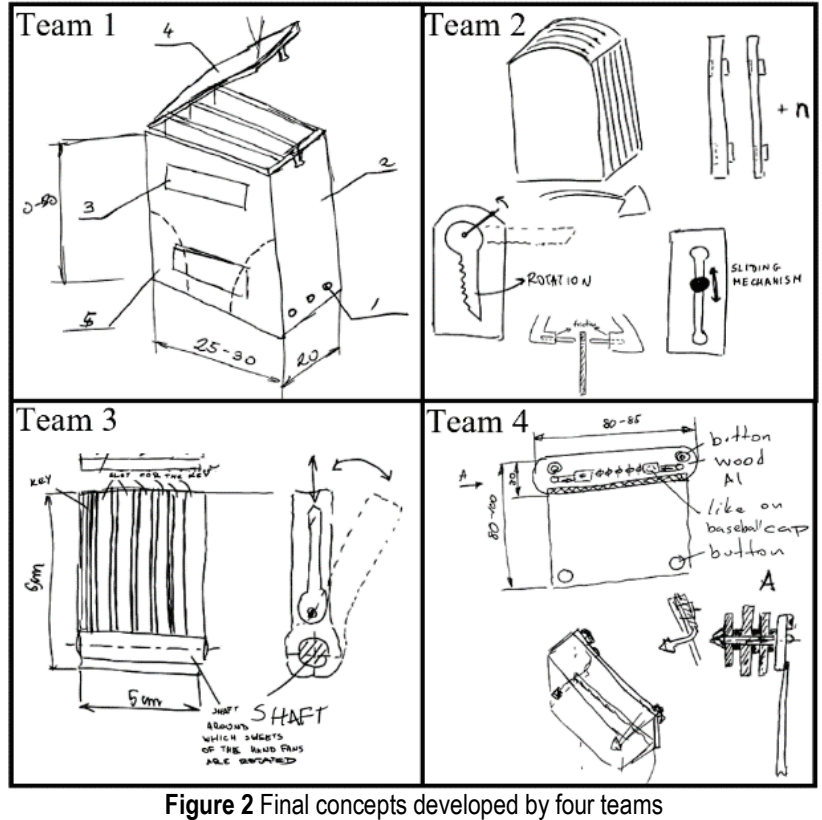

\subsection{Number of Turn Transitions}

Turn transitions between each pair of team members are shown in Tab. 2. In the table, a cell value in the $i$-th row and $\mathrm{j}$-th column represents the number of times a turn has been taken from a team member in the i-th row by a team member in the j-th column. The number of turn transitions between a pair of team members ranges from 100 to 198 $($ Mean $=135.7, S D=32.3)$. The row with "Turns" label shows the overall number of turns taken by each team member, regardless of a previous turn holder. The values range from 218 to 329 (Mean $=271.4, S D=35)$. Pearson's chi-squared goodness of fit test with two degrees of freedom $\left(\chi^{2}(2)\right)$ has been used to check if the turns taken by each team member differed from a uniform distribution, which would occur if the turn holders are chosen randomly. The test resulted in the statistically significant results for all teams except Team 2 (see Tab. 2). Thus, at the level of significance of $1 \%$, it can be concluded that three out of four teams do not have a uniform distribution of turns taken by each team member. Finally, the table also shows the total number of turn transitions per team, which ranges from 769 to $875($ Mean $=814.2, S D=49)$.

The number of turn transitions between each pair of team members was divided by a total number of turns for the respective team, thus enabling comparison among different teams. In other words, for calculation and analysis reported in this paper, turns between a pair of team members are regarded as a percentage of the overall number of turns in the team. Further, VIEW scores have 
been transformed on a team level to take into account the co-influences of different PS styles in a given team. First, to enable comparison and combination of the three VIEW dimensions, a min-max normalisation of the data in Tab. 1 along each dimension has been performed. The described transformation was guided by literature [20, 33] which deals with the influence of team member's diversity in general, and PS style diversity in particular, on team processes and outcomes. Normalised VIEW scores allow calculation of the diversity measures using the method proposed by Cronbach and Gleser [34]. These measures were used for assessing similarity (and, consequently, diversity) between persons' profiles and can also be used to assess how similar/different a person is from the rest of the group [34].

Table 2 Number of turn transitions between team members

\begin{tabular}{|c|c|c|c|c|c|c|c|}
\hline Team 1 & $P 1$ & $P 2$ & $P 3$ & Team 2 & $P 4$ & $P 5$ & $P 6$ \\
\hline$P 1$ & - & 107 & 114 & $P 4$ & - & 111 & 147 \\
\hline$P 2$ & 103 & - & 198 & $P 5$ & 119 & - & 123 \\
\hline$P 3$ & 118 & 193 & - & $P 6$ & 138 & 131 & - \\
\hline Turns & 221 & 300 & 312 & Turns & 257 & 242 & 270 \\
\hline$\chi^{2}(2)$ & \multicolumn{3}{|c|}{$17.6, p=0.000^{*}$} & $\chi^{2}(2)$ & \multicolumn{3}{|c|}{$1.5, p=0.472$} \\
\hline Total & 831 & Total & \multicolumn{3}{|c|}{769} \\
\hline Team 3 & $P 7$ & $P 8$ & $P 9$ & Team 4 & $P 10$ & $P 11$ & $P 12$ \\
\hline$P 7$ & - & 113 & 104 & $P 10$ & - & 107 & 188 \\
\hline$P 8$ & 100 & - & 179 & $P 11$ & 109 & - & 141 \\
\hline$P 9$ & 118 & 166 & - & $P 12$ & 187 & 143 & - \\
\hline Turns & 218 & 279 & 283 & Turns & 296 & 250 & 329 \\
\hline$\chi^{2}(2)$ & $10.2, p=0.006^{*}$ & $\chi^{2}(2)$ & $10.8, p=0.005^{*}$ \\
\hline Total & \multicolumn{9}{|c|}{780} & Total & \multicolumn{5}{c|}{875} \\
\hline
\end{tabular}

$P$ - participant; $\chi$ - Chi-squared score; ${ }^{*} p<0.01$

\subsection{PS Style and the Percentage of Turns Taken by Team Member}

The average Cronbach's $D$ [34] (from here on $D$ ) has been calculated to analyse the effect of PS style diversity on an individual level (individual to team difference). Even though $D$ can be calculated for more than one VIEW dimension, in the first set of analyses, each dimension has been considered separately. The $D$ results for each pair of dimensions are shown in Fig. 3, where three graphs represent $O C \times M P, O C \times W D$ and $M P \times W D$ sub-spaces. Position in each graph is determined by the $D$ s of the two VIEW dimensions outlined in the graph. Different symbols in graphs are used to distinguish between teams (Team 1 $\circ$; Team $2-\square$; Team $3-\Delta$; Team $4-\diamond$ ), while the size of the symbol illustrates the percentage of turns taken by the team member. These graphs serve to visually represent the relationship between the percentage of turns taken by the team member and diversity in each VIEW dimension. Fig. 3 demonstrates that observing diversity along an individual VIEW dimension (i.e. without taking into account other dimensions), does not indicate any apparent relation to the percentage of turns taken. However, from the second paragraph in Fig. 3 (i.e. a combination of diversity in $O C$ dimension and diversity in $W D$ dimension), a particular pattern seems to exist. Namely, it can be noticed that in the plot $D(O C)-D(W D)$, the team member who is closest to the origin (for a given team) has the smallest percentage of turns in the team.

In order to explore the relationship between the diversity in $O C$ and $W D$ dimensions and the number of turns in the team, the $D$ has been calculated for the two dimensions. For better visualisation and understanding of the identified relationship, the obtained $D$ of each team member has been normalised by the total team diversity in these two dimensions, respectively. Fig. 4 shows the normalised $D$ across $O C$ and $W D$ dimensions and percentage of turns. The team members can be separated into three clusters. Team members who are the least diverse from average team value have the lowest percentage of turns (dotted cluster). Team members who are the most diverse from average team value have a higher percentage of turns (solid line cluster) when compared to team members belonging to the dotted cluster. However, they have a lower percentage of turns than team members who were categorised as neither the least nor the most diverse from average team value (dashed cluster).
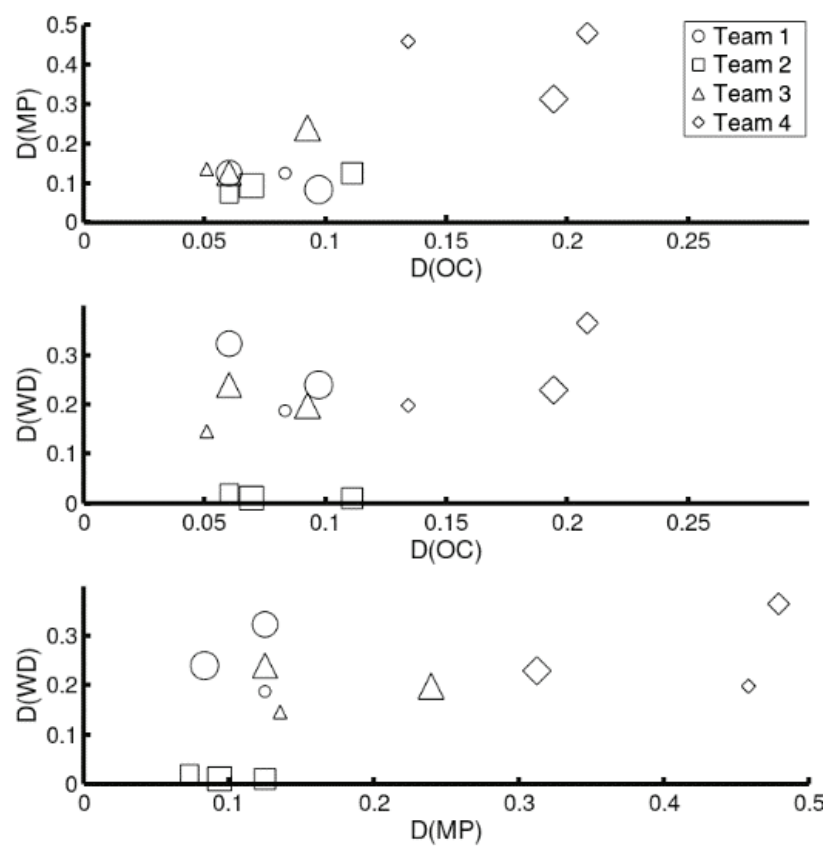

Figure 3 Relating diversity in PS style to the percentage of turns

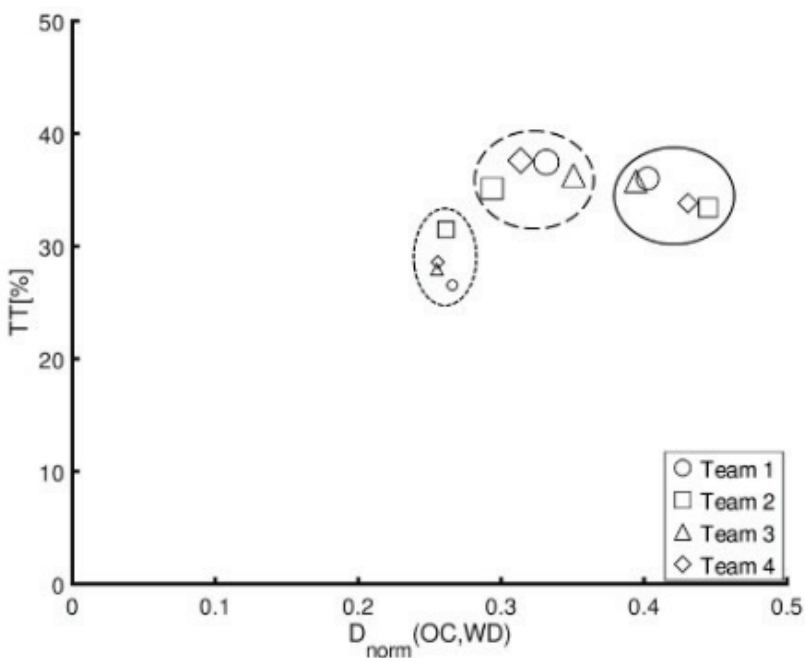

Figure 4 Relating diversity in $O C$ and WD to the percentage of turns

\subsection{PS Style and the Percentage of Turn Transitions between Team Members}

In contrast to Section 6.2 where the difference of an individual team member from the rest of the team was of interest (individual to team difference), this section 
considers the differences within any given pair of individuals (individual to individual difference). For this analysis, the PS style differences have been calculated for all pair combinations within each team. The diversity has again been calculated using the $D$, and the obtained results are normalised for the same reasons as previously described (see Section 6.2). Fig. 5 shows the diversity in $O C$ and $W D$ dimensions between each pair of team members $(T M)$ and the percentage of turns in both directions, e.g. $T M 1 \rightarrow T M 2$ and $T M 2 \rightarrow T M 1$.

The results show that there might be a non-linear relationship between the diversity of team members regarding $O C$ and $W D$ dimensions and the percentage of turn transitions between them. Pairs consisting of the most diverse individuals have the highest percentage of turn transitions (solid line cluster), while those consisting of more similar individuals have a lower percentage of turn transitions (dotted and dashed clusters).

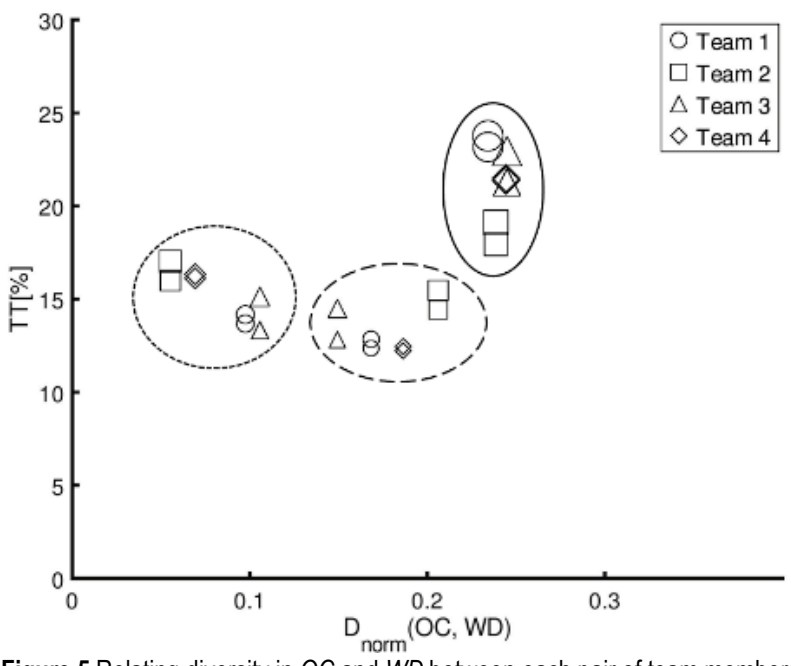

Figure 5 Relating diversity in $O C$ and $W D$ between each pair of team members to the percentage of turns

\section{DISCUSSION}

\subsection{PS Style Diversity of a Team Member}

As seen in Fig. 3, no linear relationship between any particular dimension of the PS style at the team level (measured as the average Cronbach's $D$ ) and percentage of turns exists. It might be that due to the short duration of sessions, differences in the particular dimension of PS style did not relate to the percentage of turns. Another reason might be the intricacy of team diversity depicted by the average Cronbach's Ds. For instance, when a diversity of a team member from the rest of the team was calculated combining $O C$ and $W D$ dimensions, a non-linear relationship was found between the diversity and the percentage of turns (Fig. 4).

An explanation for this non-linear relationship can be formed by referring to two team diversity-related theories [33]. Namely, based on the information/decision-making (IDM) theory, the more diverse an individual is from team average, the more knowledge they exchange. The overall increase in the percentage of turns for the two most diverse team members when compared to the least diverse team members supports the IDM theory. In contrast, the social categorisation (SC) theory suggests that if an individual is perceived as too different, they will be less involved in group information processing. The SC theory is supported by the fact that the most diverse team member has the lowest percentage of turns.

While coupling of the $O C$ and $W D$ dimensions enabled new insights about turns taken by each team member (Fig. 4), diversity in the $M P$ dimension does not relate to the percentage of turns in a team. One explanation might be a team size, which correlates with internal relations [35]. The study [35] suggests that, in smaller teams, members with higher $M P$ score (Internals) might find it easier to express their thoughts and ideas. Another explanation might be that the $M P$ dimension affects the number of turns when taken as an absolute value, since it is a measure of preferences for processing information externally or internally [19] irrespective of the team formation. The similar conclusion has been provided by Kress and Schar [36] who suggested that interpersonal mode of thinking as measured with Hermans Brain Dominance Instrument might be valuable to the team in their absolute values [36]. However, the relationship between absolute $M P$ score and number of turns is probably not straightforward since the reviewed studies did not identify the effect of extraversion (which is strongly correlated with the $M P[20]$ ) on the design process [37].

\subsection{PS Style Diversity within Pairs of Individuals}

For the same reasons as described in the previous section, analysis of the differences in PS style within pairs of individuals for any particular VIEW dimension and the corresponding percentages of turn transitions does not indicate any linear relationship. However, when the diversity was calculated for the combined effect of $\mathrm{OC}$ and $W D$ dimension, a non-linear relationship was again detected (Fig. 5). This non-linear relationship can also be deduced by considering the nearly-symmetric matrix of turn transitions (Tab. 2) and information presented in Fig. 4. Nevertheless, the results might provide a basis for developing a more comprehensive explanation of the patterns and a potential underlying relation to the two diversity-related theories described in Section 7.1. In accordance with IDM theory, the highest number of turn transitions was observed for the most diverse individuals within a team. Their different perspective on the problem [38] might result in a higher interaction and percentage of turns. It is found that people distant on the KAI scale (which correlates with the $O C$ dimension [20]) might perceive some of the other's behaviour pejoratively [17] thus leading to increase verbal communication between them.

\subsection{Reflection on Proposed Framework}

The proposed framework in Fig. 1 gives a possibility to relate the PS style on the structure of communication, verbal engagement, and utterance length, which can lead to a more comprehensive understanding of team communication. As shown in the empirical study, coupling the PS style with the turn-taking model resulted in the newly obtained insights about the effect of individual PS style dimensions on team members' communication. Furthermore, the framework can be used to explain the 
patterns and phenomena identified in previous $T T$-related research. For example, the proposed framework allows the analysis of teams of different sizes to explore phenomena such as the formation of sub-teams [14].

The proposed framework is adaptable to other individuals' characteristics (such as e.g. cognitive level and experience) as well. Therefore, it is possible to study the individual and combined effect on team verbal communication. The proposed framework could also be used to test and validate various approaches to team formation. In the design practice, the results could be used as a basis for the tool aimed at finding problems within the team (e.g. disruptions in the communication).

\section{CONCLUSIONS AND FUTURE WORK}

This paper proposes a framework for relating the PS style to turn-taking in the communication of design teams. The empirical study has shown that an analysis based on the proposed framework can reveal the relationship between PS style and team verbal communication. The results indicate that diversity in PS style might affect the percentage of turns, but that the relationship is not straightforward. However, when analysing the combined effect of the diversities along $O C$ and $W D$ dimensions, a non-linear relationship was detected. Diversity in $M P$ does not seem to affect the portion of turns, neither separately nor coupled with other VIEW dimensions.

Although the framework might improve understanding of design team communication, some limitations of the framework exist. The first limitation is the inability to describe parallel conversations (e.g. having two or more separate conversations within a team) in a design team with four or more members. Furthermore, the current framework does not include the content analysis of the communication as well as non-verbal communication, thus only addressing a limited perspective of design team interaction. Also, a larger sample is needed for more embracive statistical analysis and testing of newly identified relationships.

Future studies will aim to tackle abovementioned limitations by extending the framework and study scope. More specifically, future experiments will include teams of various sizes and compositions working on different task types with various task durations. Furthermore, additional communication aspects (e.g. content of the communication) as well as modes of communication (e.g. sketching and gesturing), will be included in the analysis.

\section{REFERENCES}

[1] Stempfle, J. \& Badke-Schaub, P. (2002). Thinking in design teams - an analysis of team communication. Design Studies, 23(5), 473-496. https://doi.org/10.1016/S0142-694X(02)00004-2

[2] Sonalkar, N., Mabogunje, A., \& Leifer, L. (2013). Developing a visual representation to characterize momentto-moment concept generation in design teams. International Journal of Design Creativity and Innovation, 1(2), 93-108. https://doi.org/10.1080/21650349.2013.773117

[3] Cash, P., Hicks, B., \& Culley, S. (2013). A comparison of designer activity using core design situations in the laboratory and practice. Design Studies, 34(5), 575-611. https://doi.org/10.1016/j.destud.2013.03.002

[4] Kan, J. W. T. \& Gero, J. S. (2017). Quantitative Methods for
Studying Design Protocols. Dordrecht: Springer Netherlands. https://doi.org/10.1007/978-94-024-0984-0

[5] Eisentraut, R. (1999). Styles of problem solving and their influence on the design process. Design Studies, 20(5), 431437. https://doi.org/10.1016/S0142-694X(99)00016-2

[6] Sonalkar, N., Jablokow, K., Edelman, J., Mabogunje, A., \& Leifer, L. (2017). Design Whodunit: The Relationship Between Individual Characteristics and Interaction Behaviors in Design Concept Generation. In Volume 7: $29^{\text {th }}$ International Conference on Design Theory and Methodology. Cleveland: American Society of Mechanical Engineers (ASME). https://doi.org/10.1115/DETC2017-68239

[7] Robson, C. \& McCartan, K. (2016). Real world research. Wiley.

[8] Goldschmidt, G. (2014). Linkography: Unfolding the Design Process. Cambridghe: The MIT Press. https://doi.org/10.1162/DESI_r_00329

[9] Sacks, H., Schegloff, E., \& Jefferson, G. (1974). A simplest systematics for the organization of turn taking for conversation. Language. https://doi.org/10.2307/412243

[10] Gero, J. S. \& Kannengiesser, U. (2004). The situated function-behaviour-structure framework. Design Studies, 25(4), 373-391. https://doi.org/10.1016/j.destud.2003.10.010

[11] Bierhals, R., Schuster, I., Kohler, P., \& Badke-Schaub, P. (2007). Shared mental models-linking team cognition and performance. CoDesign, 3(1), 75-94 https://doi.org/10.1080/15710880601170891

[12] Jiang, H. \& Gero, J. S. (2017). Comparing Two Approaches to Studying Communications in Team Design. In J. S. Gero (Ed.), Design Computing and Cognition '16 (pp. 301-319). Cham: Springer International Publishing. https://doi.org/10.1007/978-3-319-44989-0_17

[13] Gero, J. S. \& Kan, J. W. (2009). Learning to Collaborate During Team Designing: Some Preliminary Results From Measurement-Based Tools. In A. Chakrabarti (Ed.), Proceedings of the $2^{\text {nd }}$ International Conference on Research into Design (pp. 560-567). Bangalore.

[14] Gero, J. S., Kan, J., \& Jiang, H. (2014). Distinguishing and measuring "communication while designing" and "design communication" in team design. In M. Meboldt, S. Matthiesen, P. Badke-Schaub, \& Q. Lohmeyer (Eds.), International conference on human behavior in design. Ascona.

[15] Wulvik, A., Bisballe, M., \& Steinert, M. (2017). Temporal Static Visualisation of Transcripts for Pre-Analysis of Video Material - Identifying Modes of Information Sharing. In B. T. Christensen, L. J. Ball, \& K. Halskov (Eds.), Analysing Design Thinking: Studies of Cross-Cultural Co-Creation (pp. 586-602). Leiden: CRC Press.

[16] Treffinger, D. J., Selby, E. C., \& Isaksen, S. G. (2008). Understanding individual problem-solving style: A key to learning and applying creative problem solving. Learning and Individual Differences, 18(4), 390-401.

[17] Kirton, M. J. (2003). Adaption-Innovation. AdaptionInnovation: In the Context of Diversity and Change. Routledge. https://doi.org/10.4324/9780203695005

[18] Treffinger, D. J., Isaksen, S., \& Stead-Dorval, K. (2005). Creative Problem Solving: An Introduction. Prufrock Press Inc.

[19] Selby, E. C., Treffinger, D. J., \& Isaksen, S. G. (2014). Foundations of VIEW. Orchard Park, NY.

[20] Treffinger, D. J., Isaksen, S. G., \& Selby, E. C. (2014). Evidence Supporting VIEW. New York.

[21] Martinec, T., Horvat, N., Škec, S., \& Štorga, M. (2018). Verbal engagement in teams solving a conceptual design task. In $15^{\text {th }}$ International Design Conference. Dubrovnik.

[22] López-Mesa, B., Mulet, E., Vidal, R., \& Thompson, G. (2011). Effects of additional stimuli on idea-finding in design teams. Journal of Engineering Design, 22(1), 31-54. https://doi.org/10.1080/09544820902911366 
[23] Mulet, E., López-Mesa, B., Gónzalez, M. C., \& Camelo, D. (2007). Characterisation of designer interactions in the creative design process. In Proceedings of the $16^{\text {th }}$ International Conference on Engineering Design (ICED07).

[24] Sarkar, P. \& Chakrabarti, A. (2014). Ideas generated in conceptual design and their effects on creativity. Research in Engineering Design, 25(3), 185-201. https://doi.org/10.1007/s00163-014-0173-9

[25] Piirainen, K. A. (2016). Synthesizing Knowledge in Design Research. In Experimental Design Research, 233-252. https://doi.org/10.1007/978-3-319-33781-4_13

[26] Jiang, H., Gero, J. S., \& Yen, C.-C. (2014). Exploring Designing Styles Using a Problem-Solution Division. In Design Computing and Cognition '12, 12, 79-94. Dordrecht: Springer Netherlands. https://doi.org/10.1007/978-94-017-9112-0_5

[27] Dinar, M., Shah, J. J., Cagan, J., Leifer, L., Linsey, J., Smith, S. M., \& Hernandez, N. V. (2015). Empirical Studies of Designer Thinking: Past, Present, and Future. Journal of Mechanical Design, 137(2), 021101-021113. https://doi.org/10.1115/1.4029025

[28] Törlind, P., Sonalkar, N., Bergström, M., Blanco, E., Hicks, B., \& McAlpine, H. (2009). Lessons learned and future challenges for design observatory research. In International Conference on Engineering Design (ICED), 371-382.

[29] Seepersad, C., Pedersen, K., Emblemsvåg, J., Bailey, R., Allen, J., \& Mistree, F. (2010). The Validation Square: How Does One Verify and Validate a Design Method? In Decision Making in Engineering Design, 303-313. Three Park Avenue New York, NY 10016-5990: ASME. https://doi.org/10.1115/1.802469.ch25

[30] Cash, P., Elias, E., Dekoninck, E., \& Culley, S. (2012). Methodological insights from a rigorous small scale design experiment. Design Studies, 33(2), 208-235. https://doi.org/10.1016/j.destud.2011.07.008

[31] Cash, P., Hicks, B., Culley, S., \& Adlam, T. (2015). A foundational observation method for studying design situations. Journal of Engineering Design, 26(7-9), 187-219. https://doi.org/10.1080/09544828.2015.1020418

[32] Nikolić, M., Škec, S., Martinec, T., \& Horvat, N. (2019). The Role of Sketching Activities and Outcomes in Conceptual Design Phase. In Proceedings of the $22^{\text {nd }}$ International Conference on Engineering Design (ICED19). Delft.

[33] Meyer, B. (2017). Team diversity. In E. Salas, R. Rico, \& J. Passmore (Eds.), The Wiley Blackwell handbook of the psychology of teamwork and collaborative processes, 151175). Chichester: Wiley-Blackwell.

[34] Cronbach, L. J. \& Gleser, G. C. (1953). Assessing similarity between profiles. Psychological Bulletin, 50(6), 456-473. https://doi.org/10.1037/h0057173

[35] Kuipers, B. S., Higgs, M. J., Tolkacheva, N. V., \& de Witte, M. C. (2009). The Influence of Myers-Briggs Type Indicator Profiles on Team Development Processes. Small Group Research, 40(4), 436-464. https://doi.org/10.1177/1046496409333938

[36] Kress, G. \& Schar, M. (2012). Teamology - The Art and Science of Design Team Formation. In H. Plattner, C. Meinel, \& L. Leifer (Eds.), Design Thinking Research: Studying Co-Creation in Practice, 89-209. Berlin Heidelberg: Springer-Verlag.

[37] Carr, P. G., de la Garza, J. M., \& Vorster, M. C. (2002). Relationship between Personality Traits and Performance for Engineering and Architectural Professionals Providing Design Services. Journal of Management in Engineering, 18(4), 158-166. https://doi.org/10.1061/(ASCE)0742597X(2002)18:4(158)

[38] Cronin, M. A. \& Weingart, L. R. (2007). Representational gaps, information processing, and conflict in functionally diverse teams. Academy of Management Review. https://doi.org/10.5465/AMR.2007.25275511

\section{Contact information}

Nikola HORVAT, mag. ing. mech.

(Corresponding author)

Faculty of Mechanical Engineering and Naval Architecture University of Zagreb,

Ivana Lučića 5, 10002 Zagreb, Croatia

E-mail: nikola.horvat@fsb.hr

Stanko ŠKEC, PhD, Assistant Professor*

Faculty of Mechanical Engineering and Naval Architecture, University of Zagreb,

Ivana Lučića 5, 10002 Zagreb, Croatia

E-mail: stskec@fsb.hr

*Guest Assistant Professor,

Technical University of Denmark,

Management Engineering, Denmark

E-mail: stancos@dtu.dk

Marija Majda PERIŠIĆ, mag. math.

Faculty of Mechanical Engineering and Naval Architecture University of Zagreb,

Ivana Lučića 5, 10002 Zagreb, Croatia

E-mail: marija.perisic@fsb.hr

Nenad BOJČETIĆ, PhD, Full Professor

Faculty of Mechanical Engineering and Naval Architecture, University of Zagreb,

Ivana Lučića 5, 10002 Zagreb, Croatia

E-mail: nenad.bojcetic@fsb.hr 